Reprod. Nutr. Dévelop., 1986, 26 (1 B), 347-348.

\title{
Influence de l'équilibre en acides aminés de trois protéines infusées dans l'intestin grêle, sur la production laitière de la vache
}

\author{
H. RULQUIN
}

Station de Recherches sur la vache laitière,

I.N.R.A., Saint-Gilles, 35590 L'Hermitage, France.

Summary. The affect of postruminal infusion of urea, gelatin, isolated soy protein or casein were tested on dairy cows in a latin square. Milk $(\mathrm{kg} /$ day) and protein $(\mathrm{g} /$ day) yields were 21.9 and $677,22.6$ and $675,23.6$ and 713 , and 23.9 and 759 , respectively. Milk protein response increased with the amount of essential amino acids infused.

Chez des vaches laitières d'un bon niveau de production, la sécrétion des protéines du lait est accrue par l'infusion post-ruminale de caséinates (Clark, 1975). Cette stimulation a généralement été attribuée à la fourniture d'acides aminés indispensables (AAI) " supposés limitants " mais elle pourrait aussi provenir de l'apport d'acides aminés glucoformateurs, ou bien d'un effet spécifique des caséinates. L'effet sur la production de lait d'un apport croissant d'AAl a été testé au cours de cet essai par l'infusion duodénale de 3 types de protéines : la gélatine, les protéines isolées de soja et le caséinate de calcium dont les AAl représentent respectivement 25,49 et $56 \%$ des acides aminés totaux.

Matériel et méthodes. Quatre vaches Pie-noires ont reçu directement dans le duodénum $75 \mathrm{~g} \mathrm{~d}$ d'azote/j apportés, selon un schéma en carré latin $4 \times 4$, par l'infusion continue durant 21 jours de $160 \mathrm{~g}$ d'urée, $460 \mathrm{~g}$ de gélatine, $550 \mathrm{~g}$ de protéines isolées de soja, ou $550 \mathrm{~g}$ de caséinate de calcium. Le traitement urée, pris comme témoin, a été rendu iso-énergétique aux autres par l'infusion d'un mélange d'acides gras volatils dans le rumen.

La matière sèche de la ration (contenant) 2,25\% d'azote) était constituée de $32 \%$ de maïs déshydraté (plante entière), $24 \%$ de pulpes de betteraves déshydratées, $18 \%$ de foin de prairie naturelle, $1 \%$ d'urée, $25 \%$ d'aliment concentré. Cette ration a été distribuée afin de couvrir, en principe, les besoins énergétiques et $80 \%$ des besoins azotés.

La production de lait a été enregistrée tous les jours, sa composition étant déterminée sur 6 traites consécutives par semaine. Des mesures de flux digestifs, ont été réalisées (sans infusions duodénales) en début et fin d'essai, selon la technique du double marquage (P.E.G. et $\mathrm{Cr} 203$ ).

Résultats et discussion. Les quantités de matières azotées ingérées ont été voisines pour les différents traitements (tabl. 1). En fournissant $372 \pm 33 \mathrm{~g} / \mathrm{j}$ d'azote non ammoniacal au niveau du duodénum, la ration (infusions non comprises) a couvert les besoins azotés des vaches, contrairement aux prévisions. Cependant, comparée à l'infusion témoin, l'infusion des protéines de soja et du caséinate ont accru les productions de lait $(8$ à $9 \%)$, de matières grasses (6 à $7 \%$ ) et de protéines, principalement celles de caséines : $7 \%$ pour le soja et $15 \%$ 
pour le caséinate (tabl. 1). L'infusion de gélatine n'a, par contre entrainé qu'un accroissement léger de la production de lait sans aucune modification de sa composition (tabl. 1).

TABL. 1. Effects sur la production et la composition du lait d'infusions duodénales de protéines

\begin{tabular}{lccccc}
\hline & Témoin & Gélatine & Soja & Caséinate & E.T.M. \\
\hline $\mathrm{N}$ ingéré $(\mathrm{g} / \mathrm{j})\left(^{*}\right)$ & 419 & 9 & 10 & 8 & 4,46 \\
Lait $(\mathrm{kg} / \mathrm{j})$ & $21,9 \mathrm{a}$ & $0,7 \mathrm{a}$ & $1,7 \mathrm{~b}$ & $2,0 \mathrm{~b}$ & 0,28 \\
Protéines $(\mathrm{g} / \mathrm{j})$ & $677 \mathrm{a}$ & $-2 \mathrm{a}$ & $36 \mathrm{a}$ & $82 \mathrm{~b}$ & 13,00 \\
Taux protéique $(\mathrm{g} / \mathrm{kg})$ & $31,0 \mathrm{a}$ & $-0,5 \mathrm{a}$ & $-0,3 \mathrm{a}$ & $0,9 \mathrm{~b}$ & 0,26 \\
Taux de caséines $(\mathrm{g} / \mathrm{kg})$ & $24,1 \mathrm{a}$ & $-0,1 \mathrm{a}$ & $-0,1 \mathrm{a}$ & $1,2 \mathrm{~b}$ & 0,27 \\
Matières grasses $(\mathrm{g} / \mathrm{j})$ & $867 \mathrm{a}$ & $27 \mathrm{ab}$ & $56 \mathrm{~b}$ & $59 \mathrm{~b}$ & 9,00 \\
Taux butyreux $(\mathrm{g} / \mathrm{kg})$ & 40,0 & 0,2 & $-0,4$ & $-0,6$ & 0,47 \\
\hline
\end{tabular}

(*) Infusions duodénales et ruminales comprises. E.T.M. = écart type d'une moyenne. Les valeurs n'ayant pas les mêmes lettres différent à $\mathrm{P}<0,05$

Les réponses de la sécrétion de lait et de protéines sont donc d'autant plus élevées que la protéine infusée est riche en acides aminés indispensables. Elles vont dans le même sens que celles obtenues par Rogers et al. (1984) en comparant des infusions de farine de coton, de soja et de caséine. Elles sont plus faibles que celles obtenues antérieurement avec une infusion de caséinate (Rulquin, 1982) sans doute parce que la ration couvrait déjà les besoins azotés.

Les acides aminés glucoformateurs, le tryptophane, l'arginine et la phénylalanine n'ont pas été des facteurs limitants de la sécrétion des protéines du lait, car leurs apports ont été maximaux avec la gélatine ou avec les protéines de soja. La mesure des flux d'acides aminés dans le duodénum et dans le sang devrait permettre de déterminer plus précisément les acides aminés les plus limitants.

Clark J. H., 1975. Lactational responses to postruminal administration of proteins and amino acids. J. Dairy Sci., 58, 1178-1197.

Rogers J. A., Clark J. H., Drendel T. R., Fahey G. R., 1984. Milk production and nitrogen utilization by dairy cows infused postruminally with sodium caseinate, soybean meal, or cottonseed meal. $J$. Dairy Sci., 67, 1928-1935.

Rulquin H., 1982. Effets sur la digestion et le métabolisme des vaches laitières d'infusions d'acides gras volatils dans le rumen et de caséinate dans le duodénum. I. - Production et digestion. Reprod. Nutr. Dévelop., 22, 905-921. 